\title{
PTAH-SOCAR FUEL-COOLED COMPOSITE MATERIALS STRUCTURE
}

\section{Bouchez and S. Beyer}

One of the key points for the development of dual-mode ramjets operating up to Mach 8 or more is the mastery of fuel-cooled composite materials structures, which are needed, at least, for the combustion chamber. MBDA France and EADS ST have been working on the development of a particular technology for such structures taking advantage of the background of MBDA France in the field of dual-mode ramjet and fuel-cooled structures and of ASTRIUM-EADS ST in the field of high-temperature composite materials. They have developed an innovative technology for advanced monobloc cooled $\mathrm{C} / \mathrm{C} / \mathrm{SiC}$ structures. The paper gives an updated status of the development of Paroi Tissée Application Hypersonique - Simple Operational Composite for Advanced Ramjet (PTAHSOCAR) technology, including test results, and presents some results obtained during system and demonstrator studies.

\section{NOMENCLATURE}

$\begin{array}{ll}e & \text { wall thickness }(\mathrm{m}) \\ h_{g} & \text { heat transfer coefficient }\left(\mathrm{W} / \mathrm{m}^{2} / \mathrm{K}\right) \\ K & \text { permeability }\left(\mathrm{m}^{2}\right) \\ \mathrm{M}_{f} & \text { flight Mach number } \\ P & \text { pressure } \\ P_{\text {duct }} & \text { hot gas pressure } \\ P_{\text {cooling }} & \text { pressure in cooling channel } \\ S & \text { frontal area }\left(\mathrm{m}^{2}\right) \\ T_{a w} & \text { adiabatic wall temperature }(\mathrm{K}) \\ T_{w} & \text { hot wall temperature }(\mathrm{K}) \\ \Delta P & \text { pressure difference } \\ \mu & \text { dynamic viscosity }(\mathrm{Pa} \cdot \mathrm{s}) \\ \rho & \text { density }\left(\mathrm{kg} / \mathrm{m}^{3}\right)\end{array}$

\section{Acronyms}

CMC Ceramic Matrix Composite

CVI Chemical Vapor Infiltration 


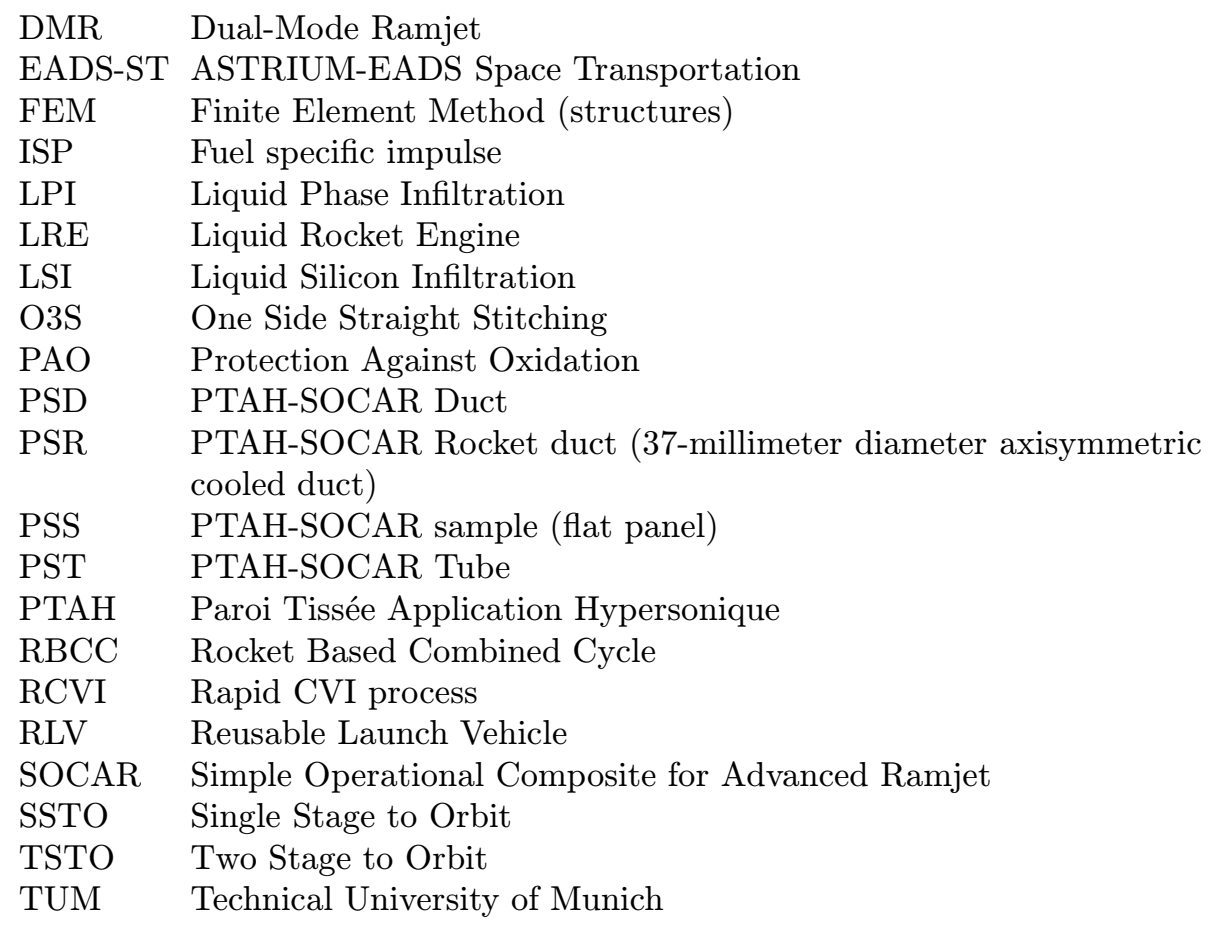

\section{INTRODUCTION}

Advanced cooled structures have been studied worldwilde for application to heat exchangers, high speed vehicles, scramjets, and dual-mode ramjets (DMR) (subsonic, followed by supersonic combustion) [1-3] as well as future liquid rocket engines (LRE) [4]. They use high-temperature materials, metallic and more and more composite $(\mathrm{C} / \mathrm{SiC}, \mathrm{SiC} / \mathrm{SiC}, \ldots)$. Different cooling techniques are used. To achieve performance and to limit the risk, the cooled structures are combining these different existing possibilities, leading often to complex and costly structures.

The present paper gives an updated status of the development of PTAHSOCAR technology, including test results, and presents some results obtained during system and demonstrator studies both for DMR and LRE (and other systems).

The propulsive performance (thrust, consumption) of the DMR have to be optimized, computed, and at-best demonstrated. But another major concern is the capacity to build such an engine, and to estimate its robustness and its weight. Light high-performance metallic or composite fuel-cooled structures are needed, at least, for the combustion chamber [5]. Several circuits of active cooling 

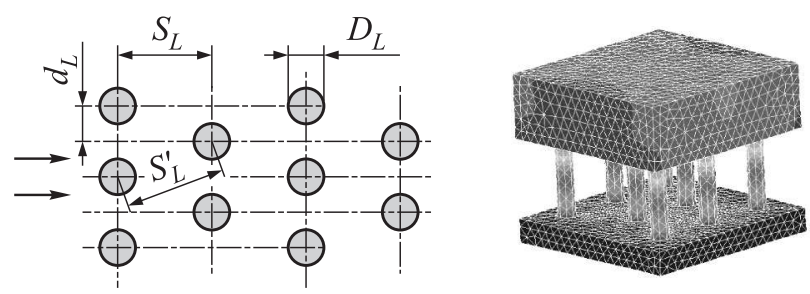

Figure 1 Pin fin configuration of cooling channel

systems had been compared to ensure good behavior of engine walls, with respect of the combustion-required fuel mass flow. Many configurations of cooling are envisaged, such as series of channels of rectangular shape or pin fins channels. The pin-fin circuit (Fig. 1) was confirmed as more efficient [6] than the more classical machined-channels.

One of the interest of the pin-fin circuit is the easy management along the walls of the DMR combustor, which is often diverging.

The interest of using composite structures (able to operate at temperature over $1800 \mathrm{~K}$ in oxidizing environment and with a typical density of $2000 \mathrm{~kg} / \mathrm{m}^{3}$ ) have been demonstrated thanks to several analytical and computational studies and to actual technology experimental testing (benefit in weight, thermal capability, injection strut drag, etc.) [5]. The mass comparison between a metallic and a carbon/carbon structure for the same DMR has been evaluated $[7,8]$ showing 30 percent benefit in weight.

This innovative cooperation on cooled high-temperature composite structures between what are now EADS ASTRIUM and MBDA France was launched in 1993, up to the test of the St-Elme [9] injection strut in 1997. Several manufacturing processes can be used for the transformation of the preforms to composite complete structures (C/C or C/SiC, CVI, LPI, LSI routes, ...). The LPI and LSI routes are mostly development in the German part of EADS [10]. Besides material and process development, this ceramic-LRE-oriented project [11] also encompasses the development of special metal/ceramic and ceramic/ceramic joining techniques as well as studying and verifying NDI (Non-Destructive Investigation) processes for the purpose of testing components.

The PTAH-SOCAR technology takes benefit of this background and takes most of the advantages of the different techniques with minimizing the drawbacks.

\section{COMPOSITE PTAH-SOCAR TECHNOLOGY}

This work is a cooperative effort between MBDA France (Le Plessis Robinson and Bourges), EADS-ASTRIUM-Space Transportation in Ottobrunn and Bor- 
deaux, EADS- "innovative works" (formerly "CRC") in Ottobrunn, Toulouse and Suresnes, with some laboratories and subcontractors.

\section{PTAH-SOCAR Genesis}

This in-house Effort of MBDA FRANCE and EADS-ST leads to low-cost, highly reliable, effective Fuel-Cooled Structure Technology. The patented idea has been to develop and preliminarily check a concept of $\mathrm{C} / \mathrm{SiC}$ structure with the following advantages:

- no bonding system (nor brazing, nor gluing, etc.);

- complete combustion chamber structure in one part ("monobloc");

- limitation of connecting problems;

- no problem for realizing corners of a two-dimensional (2D) combustor;

- limitation of possible leakage problems;

- no need of machining internal channels; and

- easier integration of specific systems (injectors, flame-holders, etc.).

The main ideas for the manufacturing of a whole DMR engine with PTAH are the following:

- monobloc actively-cooled combustion chamber obtained at preform state before its densification process (whatever this one is $\mathrm{C} / \mathrm{C}$ or $\mathrm{C} / \mathrm{SiC}, \mathrm{CVI}$ or LSI);

- linking by stitching of complex woven preforms;

- hot and cold skins linked together by stitching with carbon yarn;

- stitching treads go through the cooling channel (Fig. 2); and

- back structure needed to hold the combustion chamber pressure (may be external or integrated at preform state, based on carbon honeycomb, corrugated skin, or a system of One Side Straight Stitching (O3S) assembled stiffeners).

The PTAH-SOCAR specific weight for the heat protection system is lower than $10 \mathrm{~kg} / \mathrm{m}^{2}$ (density of this CMC material is close to $2000 \mathrm{~kg} / \mathrm{m}^{3}$ ). With the back structure, the total specific weight is $30 \%$ lighter than that of metallic advanced cooled structures. 
The necessary models of the cooled structure and the associated feasibility were checked on the basis on gazeous densification, leading to $\mathrm{C} / \mathrm{C}$ or $\mathrm{C} / \mathrm{SiC}$ cooled structures. The period 1999/2001 was used to check with limited amount of funding and aggressive time schedule the key-points of the PTAH-SOCAR technology, as summarized in Table 1.

Details on these results and further analysis have been presented in the hypersonic conference held in Orleans, France, in

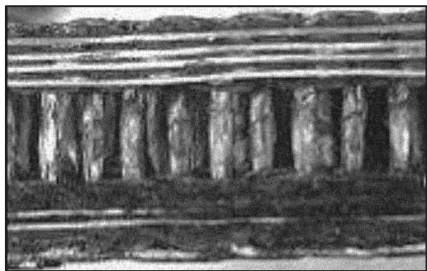

Figure 2 Straight stitched yarns from PTAH preform October 2002 [12].

The two main routes of $\mathrm{C} / \mathrm{SiC}$ densification of such structures can be summarized in Fig. 3.

The objective of the LSI Route is to create multidirectional (3D) textile structures combined with a cost-effective infiltration process, the so-called SICTEX ${ }^{\circledR}$ material. This process is based on LSI. After successful test of uncooled LSI LRE, the adaptation of the process to the PTAH-SOCAR technology was undertaken.

In 2002, the PTAH technology began to be investigated with EADS Germany partners with the cost-effective technology based on LSI. First technological results obtained essentially with the Liquid Route were presented [13] in 2003.

A baseline LSI route has been defined, preliminary characterized, and refined with two simultanate targets: to simplify the process (low risk, low cost) and to check the complete manufacturing capability on a monobloc duct able to be hot tested.

The current manufacturing process leads to straight stitching yarns as shown in Fig. 2.

Remark that the corresponding pattern is very close to the high-efficiency heat exchanger shown in Fig. 1.

Table 1 Feasibility status (based on CVI C/SiC material)

\begin{tabular}{ll}
\hline Hot test of panels & PSS1, PSS2A, PSS2B \\
Cooling effectiveness & PSS tests \\
In-shape & Manufacturing of U \\
Mechanical strength & Test and computations \\
Permeability & Integral measurement on PSS test \\
Material characterization & To be enhanced \\
System and CFD & Extensive for DMR; first idea for LRE \\
Innovation effort & Patented \\
\hline
\end{tabular}




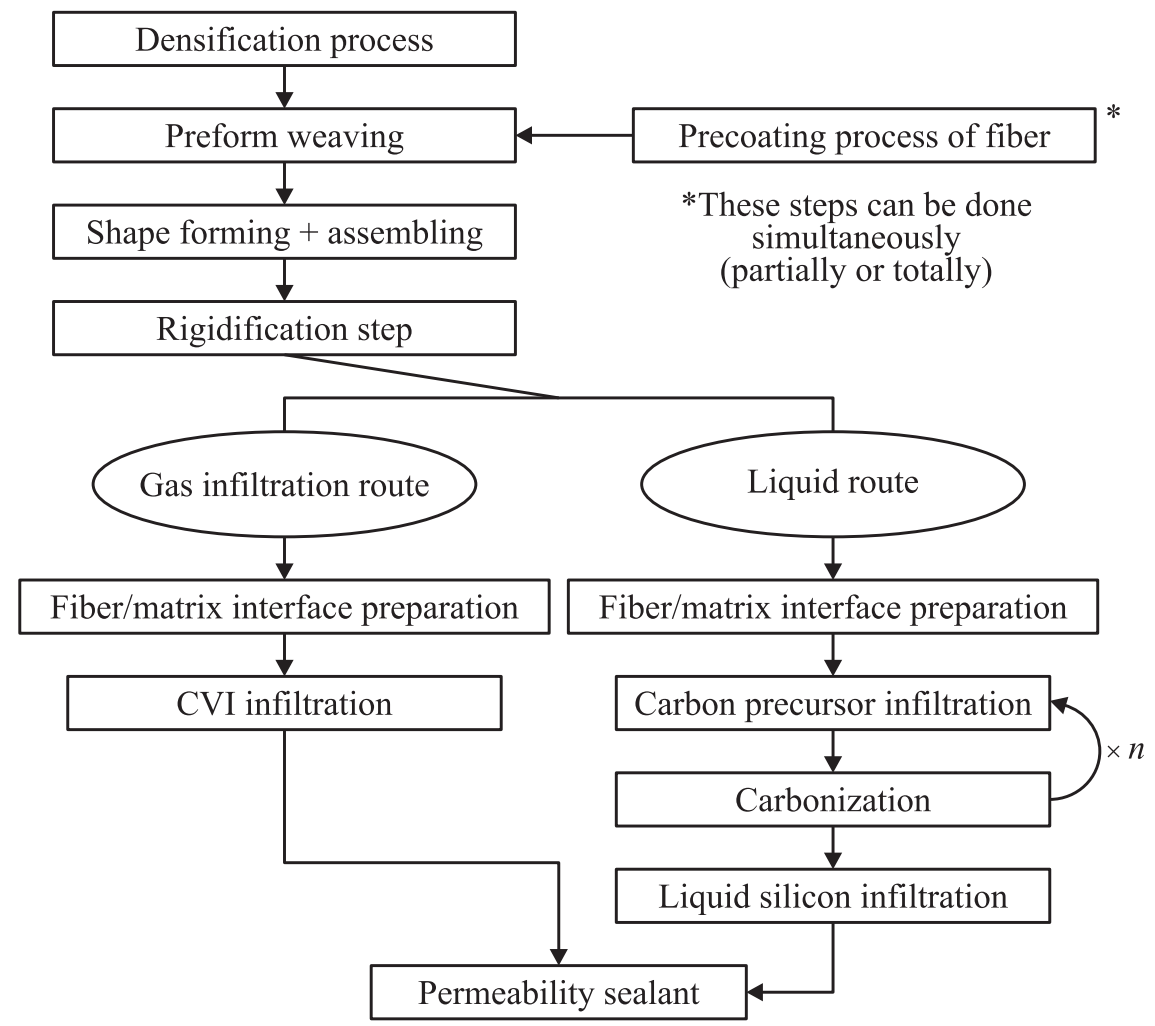

Figure 3 Among the possible manufacturing routes to obtain $\mathrm{C} / \mathrm{SiC}$ composite for PTAH-SOCAR

After some trials, the reference LSI process allows one to correctly protect the yarns [17], as shown in Fig. $4 b$.

Burst test of several PSS panels performed have demonstrated for the current PTAH-SOCAR architecture a high pressure capability. Due to tooling limitations, it was not possible to burst the panels at more than 80 and 90 bar of internal pressure. Detailed computations performed afterwards, when new mechanical characterization was performed on the new reference manufacturing process confirmed this level of mechanical strength (see Fig. 11).

This optimized RCVI-LSI process is currently the reference densification method for PTAH-SOCAR structures, the readiness of this technology is given in details in the paper presented at the 2005 Hypersonic Technologies Conference [14].

The LSI route was combined with the PTAH idea and investigated at different levels, from plate sandwich samples up to complete subscale cooled ducts. 


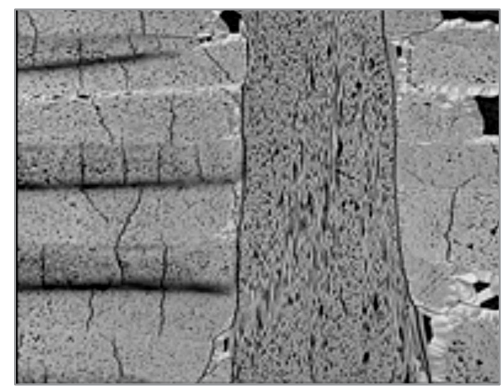

(a)

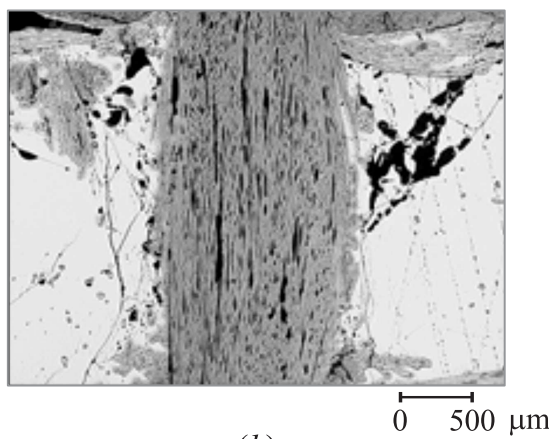

(b)

Figure 4 Undamaged yarns: CVI route $(a)$ and optimized LSI process $(b)$

For the PTAH technology, several system "paper" studies have been performed, mainly on DMRs (with hydrogen or hydrocarbon as fuel). Preliminary investigation has also been performed on LRE. The corresponding models, for example, implemented in the NANCY code [15], have been consolidated with data acquire during mechanical characterization, on the one hand, and PSS cooled panel testing, on the other hand.

\section{First Experimental Demonstration: PSS Testing}

This first experimental program was aimed at developing and testing several small cooled panels, called PSS (PTAH-SOCAR Samples), in order to:

- tune and validate the manufacturing process;

- check the mechanical resistance of the technology;

- precisely evaluate the accessible performance in terms of cooling capacity; and

- estimate the leakage with nitrogen or kerosene during hot test.

So, the PSS takes the simple shape of a plane rectangular current part of the cooled structure $(130 \times 80 \mathrm{~mm})$. PTAH-SOCAR sample is placed in a watercooled stainless steel frame which supplies the PSS with nitrogen or kerosene, to be tested at the exit of a scramjet.

The thermal behavior of a PTAH-SOCAR cooled panel has been checked during hot test, with decreasing mass flows of coolant (gaseous nitrogen, air, regular liquid kerosene). Maximum wall temperature was over $1800 \mathrm{~K}$ without damage and the cumulative duration of hot tests was 5 min for each PSS. 


\begin{tabular}{|c|c|c|c|}
\hline Coolant & Heating (scramjet, $\mathrm{ER}=0, \mathrm{ER}=1$ ) & No external heating & Test hardware \\
\hline Cold $\mathrm{N}_{2}$ & $\begin{array}{l}\text { - Thermal modeling } \\
\text { - Hot permeability } \\
\text { - Hot burst test }\end{array}$ & Cold permeability & $\begin{array}{c}\text { PSS1, PSS2A, } \\
\text { PSS2B, PSS3, } \\
\text { PSS4 }\end{array}$ \\
\hline Cold air & $\begin{array}{l}\text { Thermal modeling } \\
\text { Oxidation behavior }\end{array}$ & Cold permeability & $\begin{array}{c}\text { PSS3, PSS4 } \\
P S D \\
\end{array}$ \\
\hline $\begin{array}{c}\text { Cold } \\
\text { kerosene }\end{array}$ & $\begin{array}{l}\text { Thermal model, } \\
\text { without decomposition } \\
\text { - Coking effect on permeability } \\
\text { - First part of engine circuit }\end{array}$ & Cold permeability & $\begin{array}{c}\text { PSS1, PSS2A, } \\
\text { PSS2B, PSS3, } \\
\text { PSS4 }\end{array}$ \\
\hline $\begin{array}{l}\text { Preheated } \\
\text { air }\end{array}$ & $\begin{array}{l}\text { Thermal modeling } \\
\text { - Oxidation behavior }\end{array}$ & $\begin{array}{l}\text { - Thermal modeling } \\
\text { (inner part) } \\
\text { - Unsteady behavior } \\
\text { - Oxidation behavior }\end{array}$ & PSS3, PSS4 \\
\hline $\begin{array}{l}\text { Preheated } \\
\text { kerosene }\end{array}$ & $\begin{array}{l}\text { - Thermal model, } \\
\text { without decomposition } \\
\text { - Coking effect on permeability } \\
\text { - Last part of engine circuit }\end{array}$ & $\begin{array}{l}\text { - Thermal modeling } \\
\text { (inner part) } \\
\text { - Unsteady behavior }\end{array}$ & PSS3, PSS4 \\
\hline
\end{tabular}

Figure 5 PTAH-SOCAR cooled structures testing

The extensive testing of such panels (Fig. 5) allowed checking in actual environment the technology and the associated modeling, in a step-by-step approach.

These results have been complemented with permeability data and mechanical characterization.

\section{Permeability Results}

Leakage mass flows were roughly and integrally measured with more and more efficient techniques with $\mathrm{GN}_{2}$ and with kerosene, in order to obtain data for cold and hot permeability analysis. The available data were analyzed and compared with available information on porous structures.

The Darcy's law was confirmed to be mostly applicable in the conditions of PSS test:

$$
m=\frac{\Delta P}{\mu / \rho} \frac{S}{e} K
$$

where $K$ is the permeability, $\mathrm{m}^{2}$.

While increasing the temperature of the wall, analysis of the leakage measures of PSS panels leads to the conclusion that the permeability increases with temperature (when the coolant is nitrogen).

This result was confirmed after comparison with two test campaigns of hot permeability estimation of other thermostructural composites in different con- 
ditions. It is, nevertheless, opposite to other available results, particularly with brazed ceramic matrix composite (CMC) system [16] with unreactant gas.

If the coolant is regular kerosene, possible coking within the porous hot skin can reduce its permeability after a given time, which is difficult to be quantitatively predicted by computations but was experimentally shown.

These two effects may counterbalance.

If a particular level of transpiration is needed for a given application, the permeability can be adjusted by playing on the preform, the densification or the sealing processes. At the opposite, if leakproofness is required, for specific system requirement or simply to be able to perform a burst test of the cooling channels, an additional sealing is applied. Permeability can then vary from $10^{-11}$ to $10^{-18} \mathrm{~m}^{2}$.

\section{Mechanical Characterization}

Mechanical tests have been realized on skins (derived from sandwich) at ambient temperature and in hot conditions. Temperature increases the mechanical properties of the obtained $\mathrm{C} / \mathrm{SiC}$ skins [17]. Burst test of PSS2 panels were conducted in cold and hot conditions with the same results. Specific testing has been realized at EADS-CRC in Suresnes. Test investigates tensure, compression and shear of samples of PTAH skins as well as complete sandwiches.

Additional mechanical characterization was conducted in 2006

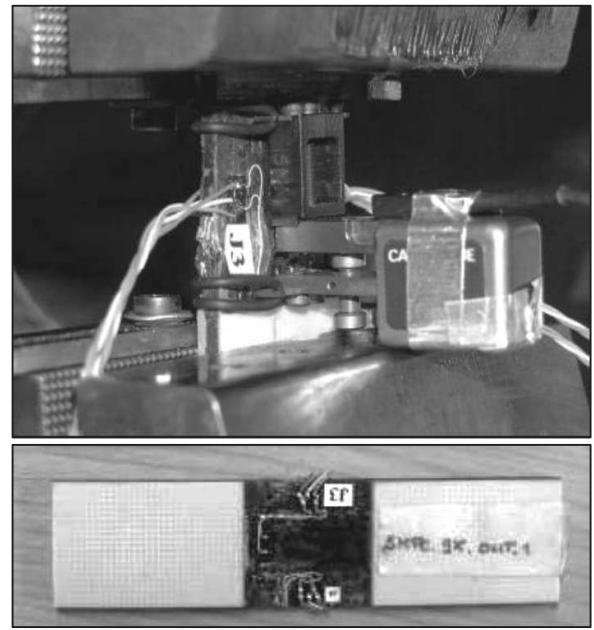

Figure 6 New compression test of PTAH skin and 2007 on skins and sandwich to take into account the last refinements of the material process as well as to use higher dimension samples (AITM* standards) (Fig. 6).

Directly from these test, as well as in connection with different Finite Element Method (FEM) computations, this work allows one to refine the material characteristics (moduli, etc.) and first level engineering limits (simple failure criteria for skins and yarns).

*AITM - Advanced Information Technologies for Management. 


\section{COMPLETE DUCTS DEMONSTRATION}

\section{Demonstration of Two-Dimensional Duct Manufacturing Capability}

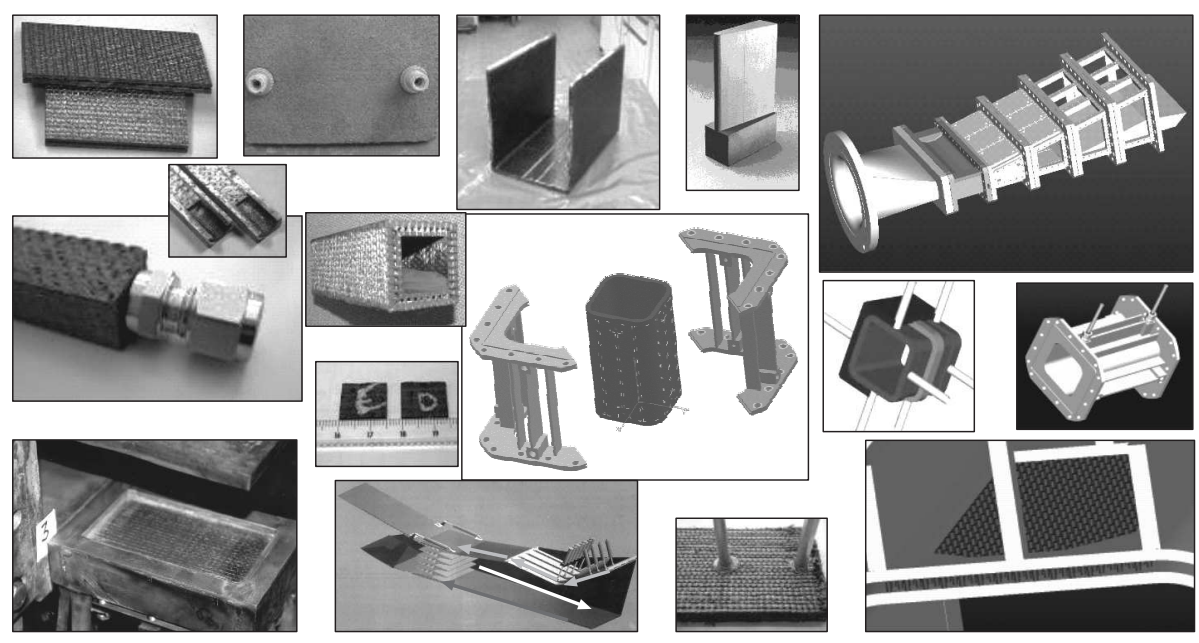

Figure 7 Example of PTAH-SOCAR step-by-step demo

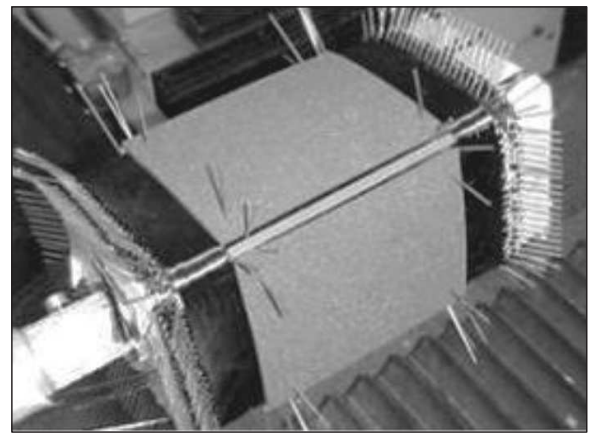

Figure 8 PTAH-SOCAR duct preform manufacturing

To check the whole process, it was decided to concentrate on the manufacturing of some subscale PTAH-SOCAR ducts, called PSD. These monobloc cooled tured, before the hot test of a cooled-duct subscale demonstrator "PSD" done in 2005 in cold conditions and, in January 2006, in hot conditions (Fig. 7).

One particular effort was made to evaluate several ways of inshape manufacturing of the PTAH-SOCAR structure, to save manufacturing time.

Figure 8 shows the channel mandrels used to generate the channel between the internal hot skin and the "cold" external one (not yet woven in this picture).

Several samples, components, or ducts were studied and manufac- 


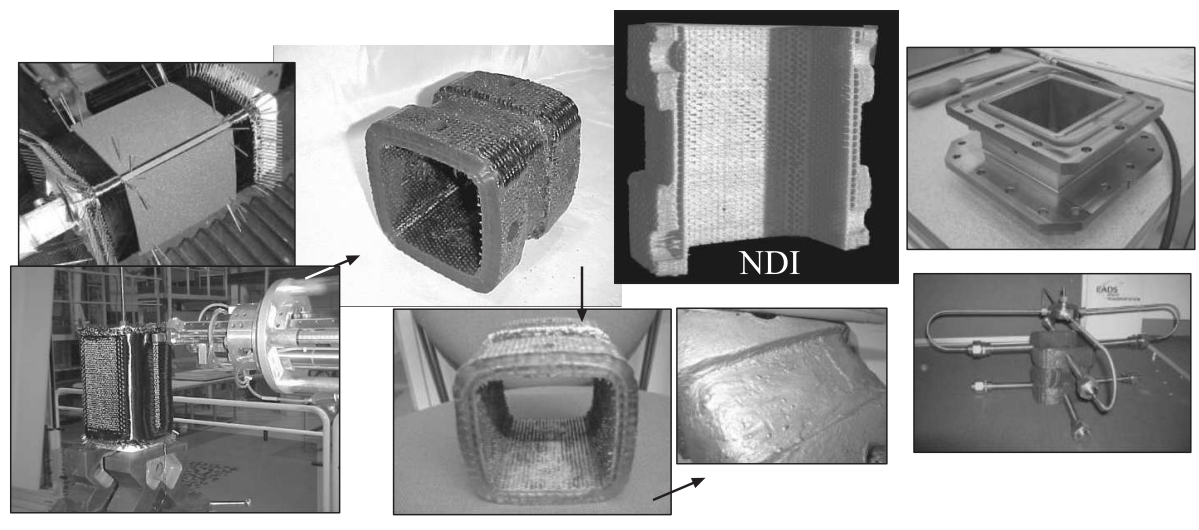

Figure 9 Manufacturing steps of PSD assembly

ducts can then be tested between metallic frame in the ONERA supersonic combustion test cell in Palaiseau, France. The complete preform is obtained on a special tooling, then transfered to the densification ovens. Additional sealing and final proof test are then realized (Fig. 9). Between each critical step, NDI is conducted, by using X-rays or neutron tomography.

Final proof test is possible thanks to the stainless steel frames and tubes compatible with the test facility.

\section{Successful Mechanical Test of PTAH-SOCAR Duct}

By using the first set of PTAH-SOCAR material characterization, some preliminary computations were realized for actual structures. The currently preferred modeling associates shells for the skins and beams for each stitched yarn, with two different computational approaches. The SAMCEF code uses here the anisotropic characteristics of the material, while the CASTOR/FEM engineering code assumes isotropy. The analyses of the yarns behavior as well as the skin stresses are similar between the two models.

The order of magnitude of the displacements as well as the maximum stresses (refered to the material ultimate one) are the same with the two approaches, as shown in details in [18]. Nevertheless, the isotropic engineering model overestimates the tensile stress in the corner yarns: the isotropic CASTOR/FEM model calculates it at $38 \%$ of the yarn ultimate stress instead of $33 \%$ with the anisotropic SAMCEF model.

In 2005, it was possible to test - in cold conditions - the pressure effect on the external skin of PSD. A laser extensometer of EADS-CRC was used to measure the maximum displacement of the central part of one external skin that 


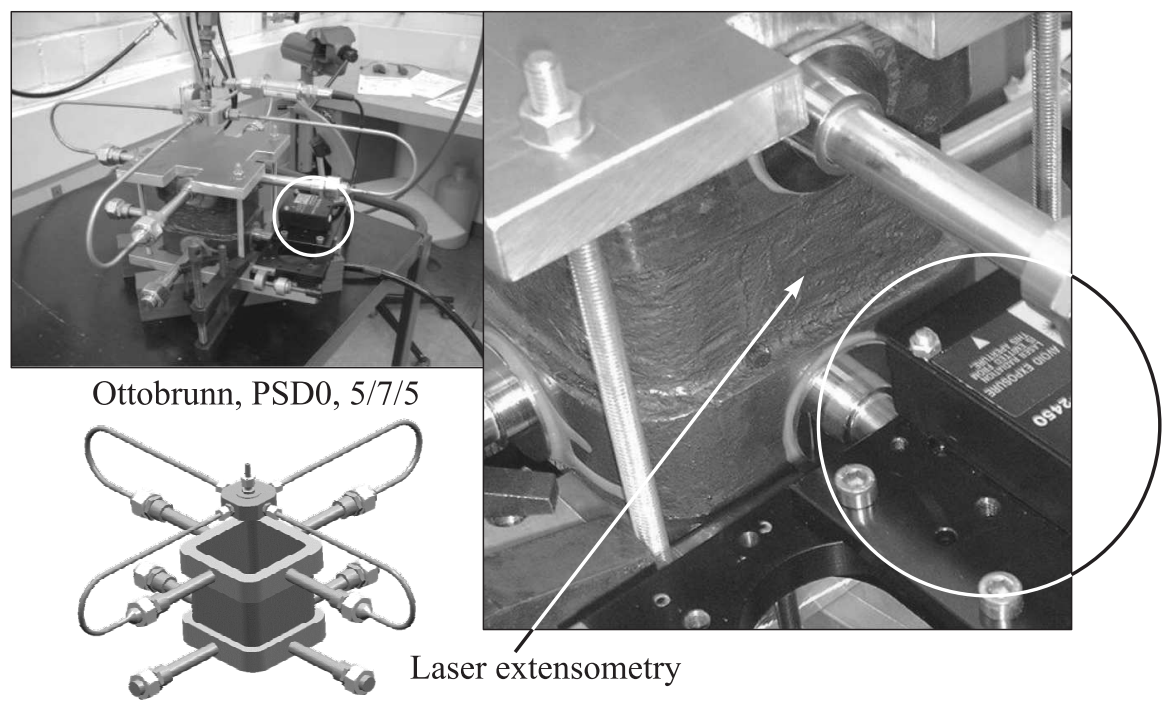

Figure 10 Cold pressure test of PSD0 with laser extensometry

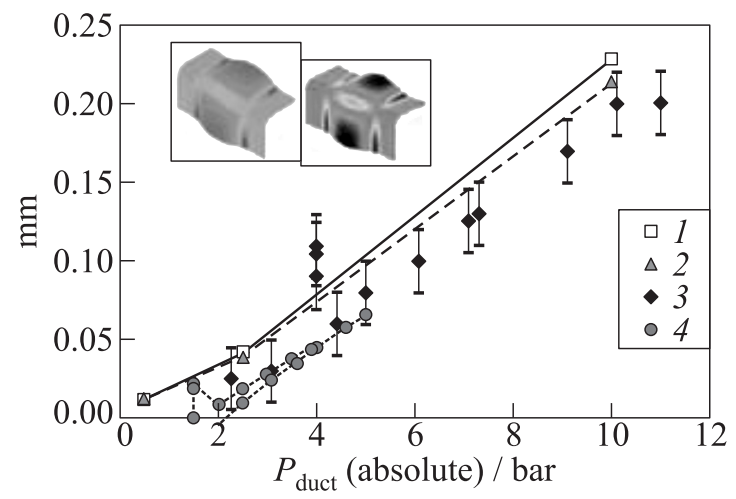

Figure 11 Computed (1 - FEM SAMCEF, 2004; and 2 - CASTOR/FEM, 2004) and measured (3 - PSD0, experiment, 05.07.05; and 4-PSD1, experiment, 27.09.05) internal pressure effect on PSD

can be compared with the precomputed one under the same pressure (Fig. 10). Pressure is increased by water in both channel $\left(P_{\text {cooling }}\right)$ and main flow $\left(P_{\text {duct }}\right)$ areas.

Figure 11 compares the two computational approaches and the extensometer results. 
Even if the geometry of 2004 computations is slightly different from the tested ducts, a good engineering agreement was found.

Moreover, work is in progress to enhance the mechanical characterization of such a structure, as well as to prepare refined computational models and failure criteria. However, the tools are considered as ready for any engineering design of a PTAH-SOCAR engine.

\section{Successull Hot Testing of PTAH-SOCAR Duct in Scramjet Environment}

After this nondestructive mechanical characterization, the PSD1 duct has been sent at the end of 2005 to ONERA Palaiseau test center in order to be tested in hot conditions.

The characteristics of the test series held in ATD5 test cell on an existing supersonic combustion chamber were the following:

- flight conditions: Mach number 7.5;

- supersonic combustion air $/ \mathrm{H}_{2}$;

- transient behavior; and

- air as coolant (no other coolant was usable).

Incoming mass flow, coolant air pressures, and temperatures were measured as well as $T_{\text {back }}$ (external wall) by Thermocouples and infrared (IR) camera. The displacement laser sensor provided by EADS-CRC was used.

The PSD1 was tested in hot conditions during the whole planned test program, which included a stepby-step approach and severe threedimensional (3D) effects on cooling between the 4 faces (each PSD side communicates internally with its neighbors through the corner, and each has its own input and output). Twelve hot runs were performed.

As far as known, it was the first successfull scramjet hot test of a monobloc cooled $\mathrm{C} / \mathrm{SiC}$ duct. De-

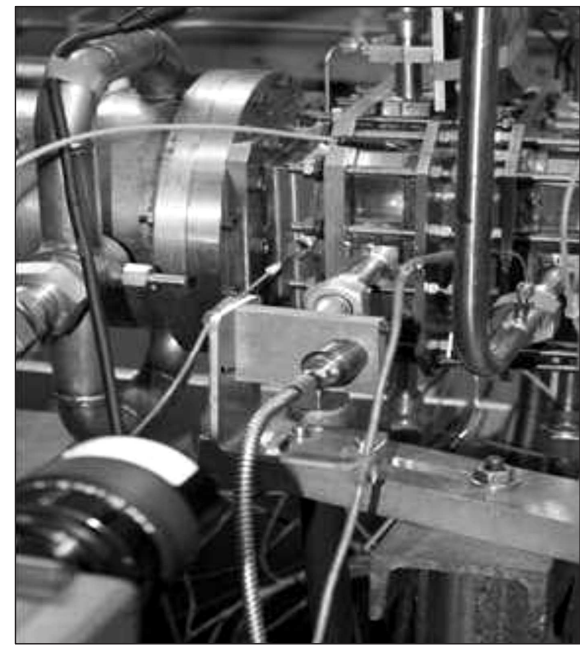

Figure 12 PSD1 cooled duct in ATD5 test bench 
tails can be found in [18]. The information given by the IR camera (visible on the bottom left part of Fig. 12) are similar to the level given by the corresponding $T_{\text {back }}$ thermocouples.

After these successfull PSD test series, work is going on with the development of PTAH-SOCAR technology.

\section{OTHER TESTS}

After test and analysis of such subscale ducts, greater structures are planned to be manufactured and tested, for example, within the hypersonic METHYLE test facility in Bourges [19]. To prepare these further DMR demonstration, as well as to investigate PTAH application to actual systems, models and technology results are available, for cooling (thermics and permeability) and for mechanics.

Many applications of PTAH-SOCAR cooled structures are under investigation (DMR, LRE, fuel cells, heat exchangers, microcombustion, transpiration cooling, etc.).

In connection with the applied structures, the data base is under enhancement thanks to basic experiments (mechanical or thermal characterization, environment compatibility, etc.). Some cooled axisymmetrical PTAH structures will be tested, particularly in oxygen/kerosene high pressure environment, within the ATLLAS project [20].

\section{Liquid Rocket Engine Application}

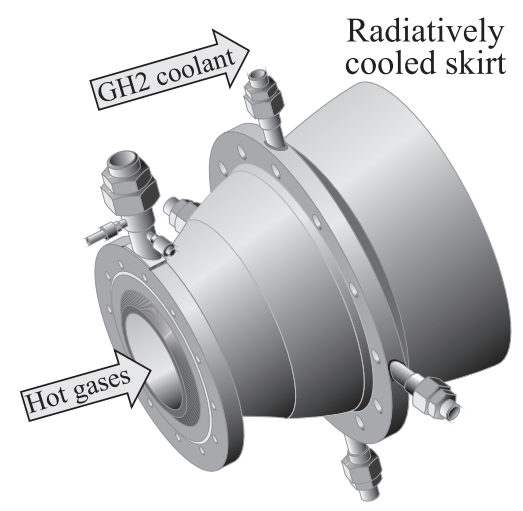

Figure 13 Project of subscale PTAH LRE nozzle extension
Preliminary investigations of the possibilities and interest of using the PTAH technology for axisymmetric LREs have been performed and presented in Joint propulsion conference [17] in 2004.

Manufacturing process adaptation and mechanical strength estimation have shown possible interest. It seems quite easy to manufacture the cooled part of the engine and the uncooled part of the nozzle in the same process with CMC material. Antileakage treatment can be limited to external skins and combustor part, leading to transpiration positive effect at the throat region. 
After some preliminary studies, a project of subscale LRE nozzle extension has been drawn (Fig. 13).

This common definition phase has included PTAH cooling circuit computations with existing models. Results with the NANCY code [15] are detailed in [18], with $\mathrm{H}_{2} / \mathrm{O}_{2}$ combustion at mixture ratio 6 and combustion pressure of 100 bar and $\mathrm{GH}_{2}$ cooling.

This PTAH nozzle extension design is under refinement, and will take benefit of the new technological characterizations of PTAH structures, especially PSR hot testing.

\section{Test of Simple PTAH-SOCAR Rocket Ducts in Liquid Rocket Engine Environment}

Manufaturing and test of such LRE nozzle extensions are planned before 2010 .

In the mid-time, within the scope of the ATLLAS program [20], some small diameter PTAH structures will be tested in a kerosene-oxygen rocket combustion chamber under various conditions.

Previoulsy, some metallic cooled systems as well as radiatively-cooled CMC ducts had been tested in a smaller LRE water-cooled test chamber located at Munich university center (TUM) at Garching in Germany [21].

Figure 14 shows one CAD assembly of PTAH 37-millimeter diameter PSR cooled duct to be tested at TUM under LRE environment.

The PSR cooled duct in Fig. 14 is equipped with integrated small shoulders and assembled into a watercooled modular LRE facility.

In the TUM facility, a wide range of mixture ratio as well as coolant mass flow can be investigated with a combustion chamber pressure up to

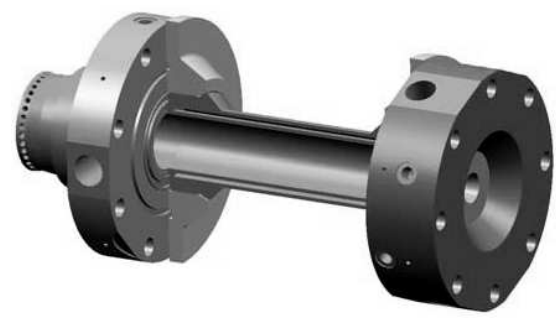

Figure 14 Assembly of $37 \mathrm{~mm}$ diameter PTAH duct for LRE testing 100 bar. PTAH-SOCAR rocket duct test series are planned up to 2008, in a step-by-step approach comparable to the PSS one (see Fig. 5). No preheating of the coolant is planned for the test at TUM.

Preliminary thermal and mechanical computations were performed with NANCY code and simple buckling analysis (no back structure is planned for these $37 \mathrm{~mm}$ diameter PSR test). These test series will allow one to investigate the PTAH materials compatibility in high-pressure LRE environment, with hydrocarbon, water, $\mathrm{CO}_{2}$, and oxygen medium. 


\section{PTAH-SOCAR Tube}

The work led by MBDA France on advanced cooled technologies includes many studies. By the coupling of NANCY and SENKIN, engineering computations allow the changes of physical properties of the fuel (modeled as $\mathrm{C}_{12} \mathrm{H}_{26}$, for example) with its chemical decomposition to be taken into account [22]. Some projects investigate the capability of equipping such cooled structures with specific measurements on the decomposed coolant [23].

To evaluate such a possibility and to perform basic experiments on PTAHSOCAR pin-fin tubes, design and manufacturing of a PTAH-SOCAR tube (PST1) was made. This tube is to be tested in a high-temperature oven with a small mass flow of hydrocarbon in an existing academic test bench at Bourges, which used metallic tubes so far.

\section{CONCLUDING REMARKS}

Composite cooled materials would give high benefit to high speed propulsion. PTAH technology is an innovative solution based on existing background of MBDA FRANCE and EADS-ST. The PTAH-SOCAR concept is very promising, whatever the densification process to be chosen.

The technology has been investigated and its feasibility had been demonstrated (hot test of several panels "PSS," in-shape pieces, etc.). Detailed analysis has been performed, with particular emphasis to material characterization and hot permeability estimation. In addition to already used gaseous densifications, LSI was confirmed to be a promising way, suitable to PTAH-SOCAR technology and very cost-effective. Liquid silicon infiltration is now the reference process and deals with "short" densification time (days instead of weeks for CVI). This second PTAH-SOCAR technology phase was considered as achieved in 2006 after the sucessfull test series in supersonic combustion of a subscale actively-cooled complete duct (PSD1) and the associated analysis.

Work is going on, thanks to different projects, with additional characterization (including PSR small-duct high-pressure GOx/kerosence testing), to prepare the manufacturing and test of PTAH larger structures of DMR and LRE in actual environment.

\section{ACKNOWLEDGMENTS}

The French Government (DGA) decided to support part of this in-housedeveloped technology, particularly, on PSD1 manufacturing and testing. 
The work presented here is due to the contribution of the dedicated teams and particularly of François Falempin, Emeric Daniau, Jacky Aufragne, and Christophe Bonzom from MBDA France; Patrick Peres, Stephan Schmidt, Christophe Arnoult, Georges Cahuzac, and Philip Martin from ASTRIUM-EADSSpace Transportation; Rolf Meistring, Franz Maidl, Sébastien Didierjean, Nicolas Swiergiel and Stephane Guinard from EADS-Common Research Center ("EADS Innovative works"). Test teams of ONERA (Olivier Dessornes et al.) as well as TUM ones (Sebastian Soller et al.) have also to be quoted.

\section{REFERENCES}

1. Falempin, F. 1997. PREPHA Program - system studies synthesis. XIII ISABE. Chattanooga.

2. Falempin, F., D. Scherrer, G. Laruelle, Ph. Rostand, G. Fratacci, and J. L. Schultz 1998. French hypersonic propulsion program PREPHA — results, lessons and perspectives. AIAA Paper No. 98-1565.

3. Giraudot, Th., A. Massot, L. Boselli, and B. Talbot. 2002. Dual-fueled advanced high-speed ramjets: Students paper. AIAA Paper No. 2002-5214.

4. Haidn, O. J., J. Riccius, D. Suslov, S. Beyer, and O. Knab. 2007. Development of technologies for a CMC based combustion chamber. 2nd European Conference for Aerospace Sciences (EUCASS). Brussels. Paper 4-06-03.

5. Bouchez, M. 2001. Dual-mode ramjet thermo-mechanical design and associated performance. AIAA Paper No. 2001-1918.

6. Scotti, S. J., C. J. Martin, and S. H. Lucas. 1988. Active cooling design for scramjet engines using optimisation methods. AIAA Paper No. 88-2265.

7. Bouchez, M., X. Montazel, and E. Dufour. 1998. Hydrocarbon fueled airbreathing propulsion for high speed missiles. AIAA Paper No. 98-3729.

8. Bouchez, M. 1999. High speed propulsion: A ten years Aerospatiale-Matra education contribution. AIAA Paper No. 99-4894.

9. Peres, P., J. Lansalot, M. Bouchez, and E. Saunier. 1996. Advanced carbon/carbon injection strut for actual scramjet. AIAA Paper No. 96-4567.

10. Beyer, S., F. Strobel, and H. Knabe. 1999. Development and testing of C/SiC components for liquid rocket propulsion applications. AIAA Paper No. 99-2896.

11. Beyer, S., H. Knabe, S. Schmidt, H. Immich, R. Meistring, and A. Gessler. 2002. Advanced ceramic matrix composite materials for current and future technology applicaton. 4th Conference (International) on Launcher Technology "Space Launcher Liquid Propulsion". Liege, Belgium.

12. Bouchez, M., F. Falempin, G. Cahuzac, and V. Avrashkov. 2002. PTAH-SOCAR fuel-cooled composite material structure. AIAA Paper No. 2002-5135.

13. Bouchez M., G. Cahuzac, and S. Beyer. 2003. PTAH-SOCAR fuel-cooled composite materials structure in 2003. AIAA Paper No. 2003-6919. 
14. Bouchez, M., and S. Beyer. 2005. PTAH-SOCAR fuel-cooled composite materials structure for dual-mode ramjet and liquid rocket engines -2005 status. AIAA Paper No. 2005-3434.

15. Bouchez, M., E. Dufour, and E. Daniau. 2006. Semi-empirical and CFD analysis of actively cooled dual-mode ramjets: 2006 status. AIAA Paper No. 2006-8073.

16. Bouquet, C., A. Luc-Bouhali, B. Hauber, and J. Thebault. 2003. Validation of a leak-free C/SiC heat exchanger technology. AIAA Paper No. 2003-6918.

17. Bouchez, M., S. Beyer, and G. Cahuzac. 2004. PTAH-SOCAR fuel-cooled composite materials structure for dual-mode ramjet and liquid rocket engines. AIAA Paper No. 2004-3653.

18. Bouchez, M., and S. Beyer. 2006. PTAH-SOCAR fuel-cooled composite materials structure for dual-mode ramjet and liquid rocket engines - 2006 status. AIAA Paper No. 2006-8072.

19. Falempin, F., M. Bouchez, L. Serre, C. Bruno, and P. Hendrick. 2004. A minimum R\&T program on air-breathing propulsion for Europe. 55th Astronautical Congress (International) 2004. Vancouver, Canada. IAC-04-S.5.01.

20. ATLLAS: Aerodynamic and thermal load interactions with lightweight advanced materials for high-speed flight. www.esa.int/techresources/atllas.

21. Soller, S., R. Wagner, C. Kirchberger, H.-P. Kau, P. Martin, and C. Maeding. 2005. Characterisation of combustion and heat transfer using GOx/kerosene in a single-element rocket combustor. AIAA Paper No. 2005-4529.

22. Daniau, E., M. Bouchez, R. Bounaceur, F. Battin-Leclerc, P. M. Marquaire, and R. Fournet. 2003. Contribution to scramjet active cooling analysis using $n$-dodecane decomposition model as a generic endothermic fuel. AIAA Paper No. 2003-6920.

23. Daniau, E., M. Bouchez, O. Herbinet, P. M. Marquaire, N. Gascoin, and P. Gillard. 2005. Fuel reforming for scramjet thermal management and combustion optimization. AIAA Paper No. 2005-3403. 